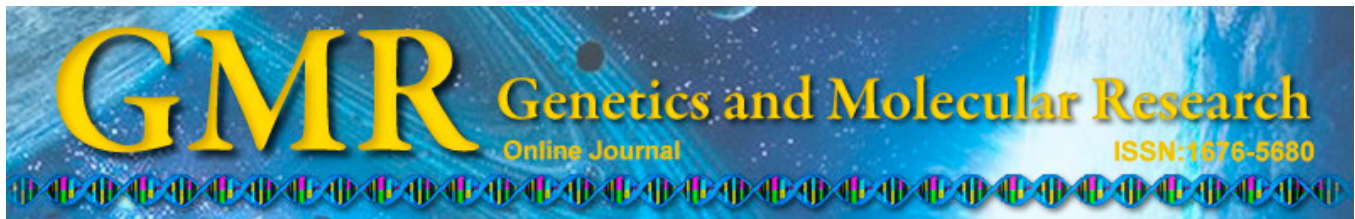

\title{
Development and characterization of polymorphic microsatellite loci in the sea cucumber Holothuria leucospilota
}

\author{
G. Dai ${ }^{1,2}$, Z.B. Li ${ }^{1,2}$, J.B. Shangguan ${ }^{1,2}$, Y.F. Ning ${ }^{1,2}$, H.W. Deng ${ }^{1,2}$, \\ Y. Yuan ${ }^{1,2}$, Y.S. Huang ${ }^{1,2}$, H. Yang ${ }^{1,2}$ and J. Lu ${ }^{1,2}$ \\ ${ }^{1}$ Fisheries College, Jimei University, Xiamen, China \\ ${ }^{2}$ Fujian Provincial Key Laboratory of Marine Fishery \\ Resources and Eco-Environment, Xiamen, China \\ Corresponding author: Z.B. Li \\ E-mail: lizhongbao@jmu.edu.cn
}

Genet. Mol. Res. 14 (1): 538-541 (2015)

Received March 8, 2014

Accepted October 1, 2014

Published January 26, 2015

DOI http://dx.doi.org/10.4238/2015.January.26.8

\begin{abstract}
Holothuria leucospilota is a tropical holothurian species that is widely distributed in the tropical and sub-tropical India-Western Pacific Region. Eight polymorphic microsatellite loci were developed from $H$. leucospilota by using the protocol fast isolation by amplified fragment length polymorphism of sequences containing repeats and tested in 30 individuals from Hainan Island in China. The number of alleles was 2-6 and polymorphism information content ranged from 0.371-0.694. The levels of expected and observed heterozygosities varied from 0.3913-0.6701 and from 0.1154-0.7000, respectively. No significant linkage disequilibrium was detected for any pairwise combination of loci. Only loci YZHS1-42 deviated from HardyWeinberg equilibrium. These polymorphic microsatellite loci may be useful for germplasm conservation of $H$. leucospilota.
\end{abstract}

Key words: Germplasm conservation; Holothuria leucospilota; Microsatellite; Sea cucumber 


\section{INTRODUCTION}

Holothuria leucospilota, commonly known as black sea cucumber, is a tropical holothurian species that is widely distributed in shallow reef areas of the tropical and sub-tropical India-Western Pacific Region (Conand, 1998). Similarly to abalone shells or shark fins, sea cucumber is a commercially important resource for coastal populations. However, because of overfishing, the sea cucumber population has sharply declined in recent years, leading to the listing of H. leucospilota as 'vulnerable' on the Red List of Threatened Animals in Singapore (Davison et al., 2008). Studying the distribution of genetic diversity of natural stocks using molecular markers is important for developing conservation strategies, but no reports are available regarding molecular marker isolation in $H$. leucospilota. Microsatellites, also known as simple sequence repeats or short tandem repeats, are repeating sequences of 1-6 bp DNA (Schlötterer and Pemberton, 1998). They are powerful co-dominant genetic markers that have been applied in population genetic studies, linkage analysis, and germplasm conservation (Fopp-Bayat and Ciereszko, 2012). No microsatellite sequences are available in GenBank for H. leucospilota. Thus, screening for polymorphic microsatellite loci in $H$. leucospilota is very important for conserving H. leucospilota resources.

\section{MATERIAL AND METHODS}

We report 8 polymorphic microsatellite loci from $H$. leucospilota identified using the protocol fast isolation by amplified fragment length polymorphism of sequences containing repeats (FIASCO) (Zane et al., 2002). Genomic DNA was extracted from the tube-foot tissues using the Genomic DNA Extraction kit (TIANGEN, Beijing, China). The DNA was digested by the restriction enzyme MseI (Fermentas, Vilnius, Lithuania) for $3.5 \mathrm{~h}$ at $65^{\circ} \mathrm{C}$, and the digested fragments were ligated to the $M s e$ I adaptor A (5'-GACGATGAGTCCTGAG-3')/ MseI adaptor B (5'-TACTCAGGACTCAT-3') using T4 DNA ligase (Fermentas) over night at $22^{\circ} \mathrm{C}$. Linker ligated DNA was hybridized to the biotinylated probes $(\mathrm{CT})_{15}$ and $(\mathrm{GT})_{15}$, then captured with streptavidin-coated magnetic sphere particles (Promega, Madison, WI, USA) and non-annealed DNA was washed away. The recovered DNA fragments were amplified using an MseI primer (5'-GACGATGAGTCCTGAG-3') and purified by GenClean Cycle Pure Kit (Omega Bio-Tek, Norcross, GA, USA) to remove the extra adaptors and dNTPs. The purified products were ligated into the pMD19-T vector (Takara) and then transformed into Escherichia coli competent DH5 $\alpha$ cells (TIANGEN). The transformants were selected on LB agar plates containing ampicillin. Recombinant clones were amplified using universal M13 primers and the polymerase chain reaction (PCR) products were visualized on $1 \%$ agarose gels. One hundred and thirty-nine positive clones in the size range of 500-1000 bp were selected for sequencing by Majorbio Company (Shanghai, China), and 33 pairs of primers were designed using Primer Premier 5.0 (Premier Biosoft, Palo Alto, CA, USA).

All 33 pairs of primers were validated in 30 individuals of $H$. leucospilota collected from Hainan Island, China. PCR amplification was performed in a $10-\mu \mathrm{L}$ reaction volume containing $50 \mathrm{ng}$ genomic DNA, 10X Taq buffer, $2 \mathrm{mM} \mathrm{MgCl}_{2}, 0.25 \mathrm{U}$ Taq DNA Polymerase (Fermentas), $0.2 \mathrm{mM}$ dNTP, and $0.4 \mu \mathrm{M}$ primer of a gradient thermal cycler (Bio-Rad, Hercules, CA, USA) was used for the amplification reaction. PCR was carried out under the following conditions: $95^{\circ} \mathrm{C}$ for $5 \mathrm{~min}, 32$ cycles at $95^{\circ} \mathrm{C}$ for $30 \mathrm{~s}$, at annealing temperature (Table 1) for $30 \mathrm{~s}, 72^{\circ} \mathrm{C}$ for $1 \mathrm{~min}, 72^{\circ} \mathrm{C}$ for $10 \mathrm{~min}$, and then stored at $4^{\circ} \mathrm{C}$. Amplified products were resolved on $6 \%$ denaturing polyacrylamide gels in a Sequi-Gen Sequencing Cell (Bio-Rad). 
Table 1. Eight polymorphic microsatellite loci for Holothuria leucospilota.

\begin{tabular}{|c|c|c|c|c|c|c|c|c|}
\hline Locus ID & Gene Bank & Primer sequence $\left(5^{\prime}-3^{\prime}\right)$ & Repeat motif & $\mathrm{Ta}\left({ }^{\circ} \mathrm{C}\right)$ & $N_{\mathrm{A}}$ & PIC & $H_{\mathrm{O}}$ & $H_{\mathrm{E}}$ \\
\hline YZHS1-7 & KF741213 & $\begin{array}{l}\text { F: CAGACGGGAACATCACCAT } \\
\text { R: GAAACCGCACCTGACACTC }\end{array}$ & $(\mathrm{GACAAG})_{3}$ & 49 & 4 & 0.479 & 0.5000 & 0.3913 \\
\hline YZHS1-35 & KF741214 & $\begin{array}{l}\text { F: ATCCCAGCATTCTTTGTG } \\
\text { R: CAGAGTAGCTCGCATTCC }\end{array}$ & $(\mathrm{CT})_{19}$ & 49 & 3 & 0.396 & 0.5517 & 0.4518 \\
\hline YZHS1-42 & KF741215 & $\begin{array}{l}\text { F: AACCGAGACCGAACCACAA } \\
\text { R: CTGCCCTACAGAAAGTAATAACGAG }\end{array}$ & $(\mathrm{CT})_{27}$ & 57 & 4 & 0.575 & 0.1154 & $0.5214 *$ \\
\hline YZHS2-6 & KF741216 & $\begin{array}{l}\text { F: GCGACTGTTCATAGACCATA } \\
\text { R: CACATCTGACACCCCACTT }\end{array}$ & $(\mathrm{AG})_{18}(\mathrm{TG})_{11}$ & 45 & 4 & 0.535 & 0.5357 & 0.5230 \\
\hline YZHS2-15 & KF741217 & $\begin{array}{l}\text { F: TAACGGAGGGAGGGGTCA } \\
\text { R: GGGAGGAGGGGAGGAAAG }\end{array}$ & $(\mathrm{GT})_{37}$ & 50 & 6 & 0.694 & 0.6154 & 0.6701 \\
\hline YZHS2-17 & KF741218 & $\begin{array}{l}\text { F: TATAATTTGGTCGGGAACG } \\
\text { R: AGTAAAGGGGCAGCATCA }\end{array}$ & $(\mathrm{GT})_{18}$ & 53 & 3 & 0.482 & 0.6292 & 0.4753 \\
\hline YZHS2-47 & KF741219 & $\begin{array}{l}\text { F: CGAAACCCACCGAAACTG } \\
\text { R: AACCGAGACCGAACCACA }\end{array}$ & $(\mathrm{GA})_{32}$ & 45 & 2 & 0.371 & 0.3333 & 0.4911 \\
\hline YZHS2-55 & KF741220 & $\begin{array}{l}\text { F: AGACACCAAACAAGAACTCC } \\
\text { R: AGGCACTGAAGGGTAAAAT }\end{array}$ & $(\mathrm{GA})_{45}(\mathrm{GT})_{28}$ & 42 & 2 & 0.375 & 0.7000 & 0.4994 \\
\hline
\end{tabular}

$\mathrm{Ta}=$ annealing temperature; PIC $=$ polymorphism information content; $N_{\mathrm{A}}=$ number of alleles per locus; $H_{\mathrm{O}}=$ observed heterozygosities; $H_{\mathrm{E}}=$ expected heterozygosities. *Significant deviations of locus from Hardy-Weinberg equilibrium after Bonferroni's correction $(\mathrm{P}<0.00625)$.

\section{RESULTS AND DISCUSSION}

We successfully amplified 8 polymorphic loci (Table 1 ). The number of alleles per locus, polymorphic information content and observed and expected heterozygosities were calculated using POPGEN32 (version 1.32) (Yeh et al., 2000) and CERVUS 3.0 (version 2.2.3) softwares. Deviations from Hardy-Weinberg equilibrium and genotypic linkage disequilibrium were tested using POPGENE 32 (version 1.32).

The number of alleles ranged from 2-6. The polymorphism information content ranged from 0.371-0.694. The levels of expected and observed heterozygosities varied from $0.3913-0.6701$, and from $0.1154-0.7000$, respectively. No significant linkage disequilibrium was detected for any pairwise combination of loci. Most loci were in Hardy-Weinberg equilibrium ( $\mathrm{P}>0.05)$, except locus YZHS1-42, even after sequential Bonferroni's correction $(\mathrm{P}<$ 0.00625), which may be attributed to the limited number of samples tested.

These polymorphic loci represent the first microsatellites isolated for H. leucospilota, increasing the available molecular markers for this species. These loci will be useful for studying genetic diversity, population structure, and conservation strategy design.

\section{AKNOWLEDGMENTS}

Research supported by the National Natural Science Foundation of China (\#31272668), the Returned Scholars Project of the Ministry of Education of China [(\#2006)331], the Foundation for Innovative Research Team of Jimei University, China (\#2010A004), and the Program for New Century Excellent Talents in Fujian Province University [(\#2006)35].

\section{REFERENCES}

Conand C (1998). Holothurians. In: The living marine resources of the Western Central Pacific. FAO, Rome.

Davison GWH, Ng PKL and Ho HC (2008). The Singapore Red Data Book: Threatened plants and animals of Singapore. Nature Society, Singapore. 
Fopp-Bayat D and Ciereszko A (2012). Microsatellite genotyping of cryopreserved spermatozoa for the improvement of whitefish semen cryobanking. Cryobiology 65: 196-201.

Schlötterer C and Pemberton J (1998). Molecular approaches to ecology and evolution. In: The use of microsatellites for genetic analysis of natural populations - a critical review (DeSalle R and Schlerwater B, eds). Birkhäuser, Basel, 71-86.

Yeh FC, Yang R, Boyle TJ, Ye Z, et al. (2000). PopGene32, Microsoft Windows-Based freeware for Population Genetic analysis. Version 1.32. Molecular Biology and Biotechnology Centre, University of Alberta, Alberta.

Zane L, Bargelloni L and Patarnello T (2002). Strategies for microsatellite isolation: a review. Mol. Ecol. 11: 1-16. 